\title{
JUAN VILLORO Y LA MALA SUERTE. (PRE)CONFESIONES EN LOS CULPABLES
}

\author{
Berta Guerrero Almagro \\ Universidad de Murcia \\ berta.guerrero@um.es
}

\author{
Aldo Fresneda Ortiz \\ Universidad de Murcia \\ aldo.fresneda@um.es
}

RESUMEN: El sentimiento de culpa puede mover al silencio o a la confesión. En Los culpables, Juan Villoro recoge siete testimonios de siete personajes apesadumbrados por las circunstancias en las que se encuentran. Si confesar es condenarse, también puede convertirse en el inicio de una vía que conduzca a la salvación. La mala suerte que aglutina a los siete sujetos encuentra su razón de ser en la indecisión de los protagonistas, en los zarandeos que la vida o los demás les causan debido a su falta de dominio. Esta debilidad puede conducir a la queja, como estadio previo a la confesión, o a la vileza y posterior desvelo, para situarse así en la confesión propiamente dicha. A través del análisis y clasificación de estos relatos, se conocerán los conceptos de suerte, culpa, confesión y cambio desde la perspectiva del escritor mexicano.

PALABRAS CLAVE: Villoro, culpa, confesión, suerte, huida

\begin{abstract}
Guilt can drive one to silence or to confession. In Los culpables, Juan Villoro collects seven testimonies of seven characters who feel sorry for the circumstances in which they find themselves. If confession means being condemned, it can also become the beginning of a path that leads to salvation. The bad luck that brings the seven subjects together stems from the indecision of the protagonists and from the anxiety that life or others cause them due to their own lack of control. This weakness can lead to complaint, prior to confession phase, or to vileness and subsequent concerns, in order to be included in the confession itself. Through the analysis and classification of these stories, concepts of luck, guilt, confession and change will be examined from the perspective of the Mexican writer.
\end{abstract}

KEYWORDS: Villoro, guilt, confession, luck, escape

El silencio o la palabra: dicotomía radical para el que se encuentra en una situación límite. Si la consciencia no alcanza reposo, probablemente necesitará pronunciarse - lo cual supone una condena inmediata, pero al tiempo, seguramente, esa condena se torna en liberación-. He aquí uno de los dilemas que recoge Los culpables; idea que su autor, Juan Villoro, expresa en la nota de David Morán para el $A B C$ (2008) sobre la presentación del volumen: 
Mientras en el catolicismo la confesión lleva a la redención, en literatura nos volvemos culpables de aquello que hemos confesado. En cuanto pronunciamos las palabras, nos vemos condenados a las consecuencias de lo que hemos dicho [...]. Muchas veces la literatura es una confesión indirecta [...]. Al escribir no buscamos ser otro, sino ser nosotros mismos de otra manera.

Villoro distingue entre la finalidad de la confesión religiosa — la salvación — y la de la literatura - expresión, condena_-; sin embargo, aporta una idea que es posible encontrar en ambas: la conversión del sujeto sin abandonar su propia esencia. Se trata, en definitiva, de la huida del individuo de sí para encontrarse con un "yo" aparentemente similar, pero de esencia distinta. En la cita de Villoro se recoge, además, otro pensamiento: la literatura como confidencia y revelación de la intimidad del autor, pasada — eso sí- por el tamiz del sujeto y/o la historia.

Los culpables es un volumen conformado por siete "confesiones"; siete relatos ${ }^{1}$ de siete personajes que - casi sin percatarse, quizá- optan por la voz frente al silencio. En ellos se puede encontrar una reflexión sobre el papel de lo mexicano (Carrillo Arciniega, 2013: 59) y una pérdida de la identidad (Enrigue, 2008). Los sujetos homodiegéticos pronuncian sus testimonios y se condenan. No en vano el volumen se inicia con el siguiente paratexto de Karl Kraus: "Quien calla una palabra es su dueño; quien la pronuncia, es su esclavo". Esta idea del sometimiento tras el pronunciamiento gravita a lo largo de la obra. Porque hablar con sinceridad es reflejarse, hecho peligroso muchas veces para convivir en sociedad. Sin embargo, la confesión conduce también a la liberación: la mente deja de atormentarse y dirige su atención a otro camino, empieza de nuevo porque el sujeto intenta dejar atrás lo que era para ir construyéndose de otro modo. El mariachi, el trabajador con habitual jetlag, el futbolista, el escritor, el viajero amigo del Tomate, el limpiavidrios y el guionista mexicano confiesan las faltas propias o las que experimentan desde el exterior y apuestan por el cambio.

Si se parte, pues, de que las siete historias recogidas en Los culpables constituyen de un modo u otro un desvelamiento íntimo del ser, es posible establecer una clasificación de las mismas atendiendo a la perspectiva desde la que los sujetos emiten sus relatos. Siguiendo a María Zambrano en La confesión: género literario (2004), se presenta una clasificación bipartita que los engloba: la preconfesión — estadio previo a la confesión caracterizado por la queja - y la confesión — donde ya no hay lugar para la queja, sino para la aceptación y el cambio-. En todos ellos, sin embargo, es posible atisbar una circunstancia común: la indecisión. Los siete protagonistas dudan y titubean, son incapaces de actuar con resolución, lo que los impide moverse por sí mismos: son movidos por los acontecimientos. Esta falta de firmeza los lleva a sufrir eso que denominan "mala suerte": ante la incapacidad para dirigirse, sufren hechos azarosos que los conducen a la queja e, incluso, finalmente, a la actuación negativa-, tras la que inician su confesión.

\footnotetext{
${ }^{1}$ Seis cuentos y una novela corta, según se expresa en la edición de Anagrama. A este respecto, en relación con el género cuento, Juan Villoro considera en una de las entrevistas recogidas en Certidumbre del extravío que este constituye el género más complicado para un escritor. Apunta que la precisión exigida en el cuento no admite desvíos: "el cuento es la prueba de fuego por su alto nivel de exigencia; exigencia que se da en la economía de recursos: no puedes distraer la atención del lector, pretender que lo vas llevando a un mundo y divagar de pronto. En el cuento todo debe contribuir a un fin" (2002: 43).
} 


\section{La mala suerte}

El vapuleo de la realidad escapa al control del ser. La realidad azota y produce frustración ante la imposibilidad de dominarla. Esto experimentan, de modo general, los siete protagonistas de Los culpables. La mala suerte interviene y anula su turno en la partida. Sin embargo, no toda mala suerte resulta designio de un más allá: a veces se debe a un estado de desorientación que deja perdido al sujeto, a merced de los acontecimientos que devienen sin que sea capaz de actuar. Vivir sin decisión — como el "Mariachi", o el limpiavidrios de "Orden suspendido"3 - en zigzag — igual que el protagonista de "Patrón de espera" —, acomplejado con uno mismo - como el futbolista de "El silbido" o el protagonista de "Amigos mexicanos", - sabiéndose débil —el hermano de Jorge en "Los culpables"7 _ incapacitado para evitar las desgracias — como en "El crepúsculo maya" — impide al personaje actuar. Lo empequeñece y lo limita a la contemplación.

El ejemplo idóneo de personaje incapaz de decidir es el mariachi del cuento homónimo que abre el volumen; él mismo lo confiesa (vid. nota 2). No toma las riendas de su propia existencia y los acontecimientos se desarrollan sin que él mueva ficha. Busca una huida literal, en el aire — como en "Patrón de espera"—, donde la realidad parece suspenderse y solamente importa el presente. El mariachi, Julián, contempla y actúa dentro de un papel que le horroriza. Las circunstancias lo llevan dando bandazos hacia un futuro que le desagrada: "quería meterme en un jacuzzi, dejar de ser mariachi. Eso debí haber dicho: «Odio ser mariachi, cantar con un sombrero de dos kilos, desgarrarme por el rencor acumulado en rancherías sin luz eléctrica». En vez de eso, hablé de caballos" (Villoro, 2008: 10). En "Los culpables de Juan Villoro y la escritura carnavalesca en el siglo XXI mexicano", Alma Guadalupe Corona Pérez y Diana Isabel Hernández Juárez se refieren también a la condición de juguete del protagonista: "Él es una consecuencia lejana de ser culpable per se; es simplemente un juguete de todo su pretérito. Frente a éste, se deja llevar resignado, maniatado" (2011: 114). Esta falta de decisión se ve condicionada por la idea de destino: los demás ven al protagonista como vivo reflejo del mariachi ejemplar $\mathrm{y}$, puesto que sus propios ojos no cuentan, él se deja llevar a disgusto con el deseo de ser otro. ${ }^{9}$

\footnotetext{
2 "Soy un astro, perdón por repetirlo, de eso no me quejo, pero nunca he tomado una decisión. Mi padre se encargó de matar a mi madre, llorar mucho y convertirme en mariachi. Todo lo demás fue automático. Las mujeres me buscan a través de mi agente. Viajo en jet privado cuando no puede despegar el avión comercial. Turbulencias. De eso dependo. ¿Qué me gustaría? Estar en la estratosfera, viendo la Tierra como una burbuja azul en la que no hay sombreros" (Villoro, 2008: 17).

3 "Yo quería hundirme como periodista. En vez de eso, ascendí en un andamio como limpiavidrios" (Villoro, 2008: 94).

4 “«iAlgún día tomarás un vuelo directo?» preguntó antes de despedirse. Llevo una vida en zigzag” (Villoro, 2008: 32).

5 "Si alguien se interesaba en mí, sólo podía ser sospechoso" (Villoro, 2008: 45); "lo mejor de Nati es que nunca supe por qué estuvo conmigo. La razón podía ser horrenda, pero no me la dijo" (Villoro, 2008: 54).

6 "Su crónica era un despojo de mis ideas. Su única originalidad consistía en haberlas descubierto (sólo al leerlo yo supe que las tenía)" (Villoro, 2008: 113).

7 "A Jorge le hubiera parecido creíble y repugnante que yo actuara como el hombre débil que era" (Villoro, 2008: 69).

8 "Todo estaba mal desde antes de subir al coche, o desde un momento anterior, ya irrecuperable. ¿Qué designio cumplíamos cuando mezclamos nuestros alientos y creímos buscarnos en dos cuerpos?” (Villoro, 2008: 91).

9 "Considera [Catalina] que yo sólo podría haber sido mariachi. Tengo voz, cara de ranchero abandonado, ojos del valiente que sabe llorar. Además soy de aquí [...]. Mi padre me hizo grabar mi primer disco a los dieciséis años. Ya no estudié ni busqué otro trabajo. Tuve demasiado éxito para ser diseñador industrial" (Villoro, 2008: 13).
}

Berta Guerrero Almagro y Aldo Fresneda Ortiz: "Juan Villoro y la mala suerte. (Pre)confesiones en Los culpables" 
Otro punto de vista es el que refleja el futbolista de "El silbido". Si el mariachi nunca ha querido serlo pese a sus condiciones idóneas a ojos de la sociedad, el futbolista se empeña en jugar aun cuando carece de aptitudes para ello. Él quiere éxito, un buen sueldo, y acepta toda clase de propuestas; aunque es rechazado en su equipo inicial, Estrella Azul, y burlado por el que casi pierde la vida, Tucanes de Mexicali. Su frustración y falta de amor propio le impiden tanto la queja como la confesión, pues se considera un desgraciado incapaz de luchar contra sus designios — el mensaje de la galleta, el mal presagio que la china le anuncia tras adquirir el loro-; ${ }^{10}$ simplemente muestra los hechos tal cual. La historia de este futbolista es la de una liberación mediante la burla, una catarsis marcada por el ridículo y la locura. Entregado a una pasión para la que carece de verdadero talento y que casi termina con su vida, este futbolista opta por la huida mediante la mofa social: marcar un gol en propia puerta y comenzar la vida de verdad. Solamente cuando por fin se decide, hacia el final del cuento, el futuro parece cambiar de color. Es significativo el inicio de este párrafo con un "de pronto" para remarcar ese acontecimiento inesperado; una locución adverbial poco aconsejada para introducir modificaciones en un relato que, sin embargo, tan magistralmente es empleada aquí. Se muestra el cambio súbito, casi incongruente, del protagonista, que también rechina al lector:

De pronto me barrí por el balón y me quedé con él. Fue como si todo girara y el sol me golpeara por dentro. Sentí un silencio atronador, como cuando desperté medio muerto en el Nefertiti. Levanté la vista, no hacia el campo, sino hacia el cielo. Luego vi el pasto alrededor, como una isla, la última isla. Fue como si rompiera una galleta de la suerte. Todo se detuvo: el agua de la cascada eléctrica, el sudor en las mejillas de los trillizos, las manos de Nati en mi espalda, los doce equipos donde me patearon, la camiseta de la selección que nunca me puse, la aguja que buscaba mis nervios, y ya no vi nada más, o sólo vi el desierto, el lugar donde podía hacer una jugada al revés. (Villoro, 2008: 56-57)

Los personajes experimentan la mala fortuna, pero solamente la combaten con decisiones que les permiten tomar un rumbo nuevo: el hecho que marca un giro, la queja que demanda un cambio, la palabra condenatoria y salvadora.

\section{La queja como preconfesión}

María Zambrano distingue la preconfesión como estadio previo a la confesión (2004: 33). Si la desesperación conduce al desvelamiento, antes de ella se produce la queja. El sujeto no se considera culpable de su desesperación, sino que halla las causas en factores externos. Buena muestra de preconfesión es el relato titulado "El crepúsculo maya". Desde el inicio se atribuye la culpa a factores externos al protagonista: "la culpa fue de la iguana" (Villoro, 2008: 71). El eje de esta historia es un viaje por carretera marcado por los encuentros y desencuentros entre el protagonista y un amigo con el que pierde y reanuda el contacto: el Tomate. Un viaje sin otra pretensión por parte del sujeto que la huida de acontecimientos que lo avergüenzan, de

\footnotetext{
10 "Un loro que ni siquiera le gusta, como tampoco le gusta cualquier otro animal. Su única causa para la adquisición de este fue el insoportable silencio que había en su casa” (Villoro, 2008: 49).
} 
los que todavía no es capaz de hablar con naturalidad: ${ }^{11}$ se acostó con una mujer casada y el preservativo se introdujo en su vagina. El protagonista es consciente de su perfil culpable, pero aún parece que no ha sido aceptado y mucho menos confesado - aunque, sin percatarse, lo está haciendo mediante su relato- . El viaje se presenta como la escapatoria perfecta, pues confiesa que "atravesaba la zozobra de tener que enfrentar un embarazo o a un marido colérico [...], cuando el Tomate sugirió que fuéramos de viaje. Acepté en el acto" (Villoro, 2008: 76).

Escapada física del problema para introducirse en otro: el triángulo con Karla y el Tomate. Buscada por el amigo y finalmente conquistada por el protagonista - a consecuencia de una especie de revancha sentimental—, tras mantener relaciones con ella, el sujeto confiesa sentirse culpable por haber traicionado, en cierto modo, a su amigo. ${ }^{12}$ La culpa se acrecienta con el inesperado accidente final, anunciado por Karla tras la marcha de la iguana - animal especial para los mayas, constituyente de parte de su alimentación en las travesías-, pero el sujeto no se atribuye a sí mismo las consecuencias: los frenos del automóvil fallaron debido a que el cable del acelerador estaba roído. ${ }^{13}$ Sin embargo, más allá de la mala suerte, de un designio inevitable, está la decisión tomada: el encuentro con Karla que, aunque no sea desencadenante directo del accidente, sí influye directamente en el estado de la joven: ella solía sentarse en el asiento trasero, hasta que el Tomate se marchó para permitirles intimidad $\mathrm{y}$, contraria a su voluntad, hizo el viaje en el asiento del copiloto. ${ }^{14}$ El sujeto experimenta una imposibilidad de control y se queja. No se involucra porque considera que no depende de él el cambio, sino de factores externos, y apela al destino para que le explique por qué el accidente y la desgracia.

\section{Condena y salvación: la confesión}

La confesión es un relato con una intención concreta: la salida de uno mismo. Se trata de una modalidad genérica que satisface una necesidad interna, y esta no es otra que referirse a un acontecimiento angustioso que mengua —en la mayoría de casos — al hablar de él. La confesión es medio para la liberación, pero puede también ser condena. María Zambrano, en La confesión: género literario, destaca el carácter oral de este tipo de relato, lo define como una conversación "a viva voz" que no instaura un tiempo imaginario, sino que se mueve en el mismo tiempo de la vida (2004: 26). La relación de la autobiografía con la confesión es tal que se corresponde y emparenta con ella; Estébanez Calderón (1996: 67) y Wachowska

\footnotetext{
11 “...me había ocurrido algo de lo que necesitaba alejarme. Ha pasado bastante tiempo y aún no puedo hablar del tema sin vergüenza" (Villoro, 2008: 74).

12 "Fui a mi cuarto cuando rayaba el alba [...]. Me sentí feliz y culpable. Al entrar en mi habitación ya sólo me sentí culpable. Había arrojado al Tomate al agua porque nunca soporté que Sonia lo prefiriera; él tuvo la decencia de perdonarme y yo le pagaba con monedas falsas" (Villoro, 2008: 88).

13 "Nos estrellamos a tres curvas de Chichén-Itzá. El freno no me respondió. El chicote del pedal estaba roído [...]. Había dicho [Karla] demasiadas veces: «No fue tu culpa». Todo estaba mal desde antes de subir al coche, o desde un momento anterior, ya irrecuperable. ¿Qué designio cumplíamos cuando mezclamos nuestros alientos y creímos buscarnos en dos cuerpos?" (Villoro, 2008: 91).

14 "Karla quiso subir al asiento trasero. Le pedí que se sentara junto a mí. Esta vez no aludió a El sistema de los objetos: «Es el asiento de la muerte», dijo. «No soy tu chófer», contesté con un filo cortante. Ella obedeció, asustada" (Villoro, 2008: 91).
} 
(2001: 177) han apuntado las conexiones existentes. Mediante la confesión, el sujeto humillado, aplastado, olvidado - busca una salida. Al expresar su culpa huye de sí mismo y pretende una revelación que lo yerga y ampare. La desesperación y la esperanza mueven el acto de la confesión: desesperación por lo que se tiene, esperanza de alcanzar otra cosa (Zambrano, 2004: 32-33). ${ }^{15}$

En el cuento "Patrón de espera", el lector asiste a una confesión: la de un personaje desorientado entre tanto ir y venir en avión. Aquí el sujeto vive una relación minada por la esterilidad - la pareja de este, Clara, no puede quedarse embarazada - y el trasiego habitual en su trabajo — una compañía de la mejor agua insípida-. La melancolía de Clara, las ausencias del sujeto, la condición habitual de este —el jetlag — van destruyendo la confianza de la pareja. Las dudas asaltan a ambos y la lejanía sentimental entre los dos se subraya con la distancia física. Es significativo el inicio del cuento: "estoy tan a disgusto con la realidad que los aviones me parecen cómodos" (Villoro, 2008: 31). El sujeto encuentra refugio en las alturas, donde la quietud pospone cualquier decisión, ${ }^{16}$ donde las ideas también parecen elevarse, ${ }^{17}$ y llega incluso a alargar sus viajes al perder vuelos - lo que despierta la desconfianza de Clara- ${ }^{18}$ Incluso los aeropuertos lo alejan de la realidad con la que se encuentra tan a disgusto. ${ }^{19}$ Se trata, en definitiva, de constantes huidas mediante las que el personaje escapa de su realidad e incluso de sí mismo. La huida es la primera fase de la confesión:

La confesión es salida de sí en huida. Y el que sale de sí lo hace por no aceptar lo que es, la vida tal y como se le ha dado [...]. Y al salir, busca abrir sus límites, transponerlos y encontrar, más allá de ellos, su unidad acabada. Espera, como el que se queja, ser escuchado; espera que al expresar su tiempo se cierre su figura; adquirir, por fin, la integridad que le falta, su total figura. (Zambrano, 2004: 37)

Tras la confesión de su infidelidad en un viaje, el sujeto comprende que quizás también Clara pretenda escapar de la realidad que la entristece, como huye la gata que tienen, y se apresura en su regreso. La confesión certifica una culpa, pero abre al sujeto una ventana para mirar más allá de sí mismo, y así, ver situaciones en las que puede intervenir para mejorarlas: su relación de pareja.

Otro cuento que constituye una confesión indirecta mediante un guion de cine es el que da título al volumen, "Los culpables". Aquí la culpa sirve como materia artística para

\footnotetext{
15 “...cuando el hombre ha sido demasiado humillado, cuando se ha cerrado en el rencor, cuando sólo siente sobre sí «el peso de la existencia», necesita entonces que su propia vida se le revele. Y para lograrlo, ejecuta el doble movimiento propio de la confesión: el de la huida de sí, y el de buscar algo que le sostenga y aclare. La confesión comienza siempre con una huida de sí mismo. Parte de una desesperación. Su supuesto es como el de toda salida, una esperanza y una desesperación; la desesperación es de lo que se es, la esperanza es de que algo que todavía no se tiene aparezca" (Zambrano, 2004: 32-33).

16 "Suspendido, con el teléfono celular apagado, disfrutando el nirvana en el que no hay nada que decidir. La aviación es eso para mí: una manera de posponer" (Villoro, 2008: 31).

17 "Con frecuencia doy con ideas que me parecen místicas y al llegar a tierra se evaporan como una loción" (Villoro, 2008: 33).

18 "He perdido suficientes conexiones para que Clara sospeche que forman parte de un plan: 'tanta mala suerte no es normal"” (Villoro, 2008: 34).

19 "Eso me gusta de los aeropuertos. Sólo constan de tensión interna. El exterior se borra. Hay que correr en pos de una puerta de salida. Es todo. El destino se llama «puerta 6»” (Villoro, 2008: 33).
}

Berta Guerrero Almagro y Aldo Fresneda Ortiz: "Juan Villoro y la mala suerte. (Pre)confesiones en Los culpables" 
construir una historia: la de un joven que tiene relaciones con la ex novia de su hermano. ${ }^{20}$ Para crear una historia verosímil consideran necesario involucrarse hasta el punto de arriesgar la propia seguridad: "nos faltaba sentirnos culpables. Éramos demasiado indiferentes. Teníamos que jodernos para merecer la historia" (Villoro, 2008: 65). El sujeto busca dónde incriminarse y encuentra convertir la culpa en materia para el cine. Admite su falta - "el problema, mi problema, es que yo ya era culpable" (Villoro, 2008: 66) - , la deja salir mediante la escritura y se derrumba, entre lágrimas quizá, tras el descubrimiento de su hermano. Pero el protagonista busca reconstruirse, empezar de nuevo, y solicita el perdón de Jorge con la esperanza de ser otro distinto al culpable que es. Su encuentro amoroso con Lucía supone una deslealtad hacia su hermano. Esta falta mancha tanto su conciencia que solamente encuentra la limpieza de la misma a través de la confesión, el arrepentimiento y el perdón de su hermano. El cuento concluye de modo constructivo: el acto vil ha servido como alimento para el arte, y con él, se acerca a la reconciliación con uno que es él mismo, pero que ya avanza hacia otro que empieza a ser.

En el cuento "Orden suspendido", Villoro presenta a un limpiavidrios caracterizado por sus bajezas, su endurecimiento ante las desgracias y su indecisión. Desde su pequeñez, fantasea con ser superior en el andamio, donde asciende, dejando atrás la ciudad y abajo las aves. Para compensar sus vilezas, necesita junto a él a Rosalía, una mujer reflejo vivo de bondad y preocupación por el prójimo. Es significativa la metáfora establecida a lo largo del relato entre los pecados y las manchas —en la piel, ${ }^{21}$ en el cuadro, ${ }^{22}$ en el techo, ${ }^{23}$ en el asfalto, $^{24}$ en el edificio- ${ }^{25}$; manchas que el sujeto pretende limpiar constantemente, que surgen con su deseo de mal y se borran con la no ejecución del mismo. El protagonista limpia el edificio como limpia su interior a través de su reflejo en el cristal. Se muestra poco solidario, envidioso ante la suerte de seres desfavorecidos como el Chivo, capaz de cometer un asesinato. Si en el relato tiene cabida la suerte — es la llegada del alpinista lo que conlleva la conversación entre Rosalía y el Chivo y la posterior donación de ella-, es esta confesión indirecta del sujeto lo que finalmente se presenta como medio para su cambio y salvación: comienza a entender señales que nunca antes había comprendido y se abre así una opción a la esperanza. Decide, por fin, arriesgarse, jugar, dejar de contemplar y tomar partido.

La última historia del volumen, "Amigos mexicanos", muestra, de nuevo, a un sujeto atormentado por las opiniones ajenas ${ }^{26}$ y las dudas. ${ }^{27} \mathrm{Si}$ su supuesto amigo Gonzalo

\footnotetext{
20 “Luego me contó que seguía en contacto con Lucía [...]. Por primera vez pensé que el guión era un montaje para obligarme a confesar [...]. Regresé a mi silla y escribí sin parar, la noche entera. Exageré mis encuentros eróticos con Lucía. En esa confesión indirecta, el descaro podía encubrirme. Mi personaje asumió los defectos de un perfecto hijo de puta" (Villoro, 2008: 69).

21 "Odio las manchas. Inhalé demasiado cemento en la preparatoria y una noche entendí que las manchas eran arañas metidas en mi piel” (Villoro, 2008: 93).

22 “Así distinguí al pintor en la sala de juntas, en el piso dieciocho. Estaba frente a una tela gigante, blanca. Lo vi poner la primera mancha [...]. Sentí que esas manchas eran los pecados que yo llevaba dentro" (Villoro, 2008: 95-96).

23 "Desperté y vi una mancha de salitre en el techo. Tenía forma de Alaska" (Villoro, 2008: 97).

24 "Vi una mancha en la banqueta, una mancha extendida, una mancha con muchos brazos y piernas, como si la sangre hubiera tenido prisa para escurrirse y llenar varios cuerpos" (Villoro, 2008: 103).

25 "Yo podía limpiar las manchas" (Villoro, 2008: 104).

${ }^{26}$ Sobre su ex mujer, Renata, apunta el sujeto: "su confianza fue más devastadora que sus críticas: Renata me atribuyó las posibilidades que nunca tuve” (Villoro, 2008: 119).
}

Berta Guerrero Almagro y Aldo Fresneda Ortiz: "Juan Villoro y la mala suerte. (Pre)confesiones en Los culpables" 
Erdiozábal resulta un traidor por mantener relaciones con su mujer, también se convierte en su balsa salvadora: él le construye una identidad nueva — mediante un guion de cine- que entusiasma a su nueva novia, se va "convenciendo de ser otra persona, con tics repentinos y una atención desfasada, algo necesario para desmarcarme de la absurda persona que había sido hasta entonces" (Villoro, 2008: 147-148). Mediante el diálogo con Gonzalo, el protagonista reconoce su culpa en el caso del secuestro de Katzenberg ${ }^{28}$ y rompe, finalmente, con su vida anterior.

En definitiva, Los culpables conforman un volumen unitario. Las historias se hilvanan a través de una temática común — la culpa_ — y de una forma que conecta con la oralidad — un sujeto que se queja o se confiesa desde la primera persona-. Los siete personajes carecen de la fuerza necesaria para decidir sobre sus vidas y padecen los golpes de la mala suerte, consecuencia, en muchas ocasiones, de su indecisión. La clasificación establecida de las siete historias permite establecer estadios distintos en este proceso de condena y salvación. Desde la indiferencia a la admisión, pasando por la queja contra lo externo, los siete sujetos que desvelan sus oscuridades demuestran la existencia de modos diferentes de sentirse culpable.

\section{Bibliografía}

CARRILLO ARCINIEGA, Raúl: "Identidades de resistencia y el simulacro de ser mexicano en Los culpables de Juan Villoro", Chasqui. Revista Latinoamericana de Comunicación, XLII/1 (2013), 54-63.

CORONA PÉREZ, Alma Guadalupe y Diana Isabel HERNÁNDEZ JUÁREZ (2011): "Los culpables de Juan Villoro y la escritura carnavalesca en el siglo XXI mexicano". En Felipe A. RÍOS BAEZA (ed.): Juan Villoro: rondas al vigía. México, Ediciones Eón.

ENRIGUE, Álvaro (2008): "Los culpables de Juan Villoro", Letras Libres, http://www.letraslibres.com/revista/libros/los-culpables-de-juan-villoro-0, 04/09/2016.

ESTÉBANEZ CALDERÓN, Demetrio (1996): Diccionario de términos literarios. Madrid, Alianza.

MORÁN, David (2008): "Nota a la presentación de Los culpables", ABC.es, http://www.abc.es/hemeroteca/historico-03-04-2008/abc/Cultura/juan-villoro-la-

escritura-es-muchas-veces-una-confesion-indirecta_1641766368708.html, 04/09/2016.

RAMOS, Elisa (coord.) (2002): Certidumbre del extravío. Entrevista con Juan Villoro. Colima, Universidad de Colima.

WACHOWSKA, Judyta: "En torno al género literario de la confesión”, Studia romanica Posnaniensia, 28 (2001), 177-187.

ZAMBRANO, María (2004): La confesión: género literario. Madrid, Siruela.

\footnotetext{
27 “...dudo mucho en tomar el auricular. Esto último, por desgracia, resultó cierto” (Villoro, 2008: 107); “tomé uno aunque no quería" (Villoro, 2008: 128).

28 "Me recordó que en la visita anterior de Samuel Katzenberg él había inventado rituales mexicanos a petición mía. Fui yo quien lo involucró con el periodista" (Villoro, 2008: 156); "La principal fuente de sus embustes eras tú. Dijiste mamada y media para aplacar su sed de exotismo. Samuel se equivocó: su Garganta Profunda era un delirante. ¿Sabes por qué te buscó en su segunda visita? Para enterarse de lo que no debía escribir. El farsante original eres tú. Acéptalo, cabrón" (Villoro, 2008: 158).
} 
(C) Berta Guerrero Almagro

(C) Aldo Fresneda Ortiz

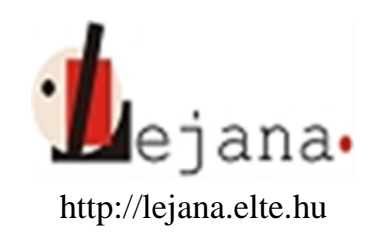

Universidad Eötvös Loránd, Departamento de Español, 1088 Budapest, Múzeum krt. 4/C

Recibido: 29 de mayo de 2016

Aceptado: 14 de julio de 2016

Berta Guerrero Almagro y Aldo Fresneda Ortiz: "Juan Villoro y la mala suerte. (Pre)confesiones en Los culpables" 